\title{
Embedding Indigenous content in Australian physical education - perceived obstacles by health and physical education teachers
}

\author{
John Williams \\ University of Canberra \\ john.williams@canberra.edu.au
}

Keywords: Indigenous perspectives, figurational sociology, physical education

\begin{abstract}
This paper is about teacher perceptions of Indigenous content in Physical Education (PE). The research question being: What obstacles if any do Health and Physical Education (HPE) teachers experience in including Indigenous mention in PE? Individual and group interviews were used to collect data from executive and classroom HPE teachers as well as Indigenous Education Officers (IEOs) at three government high schools in the Australian Capital Territory (ACT). Figurational sociology was used to interpret the findings drawing upon the notion of relative power (Elias, 1998) in particular. Busy roles, limited resources and a shortage of time were given as reasons why teachers rarely taught Indigenous content. Those teachers reported that they required professional learning to meet what they considered to be a new requirement (to include Indigenous mention) in their lessons. Teacher perceptions of obstacles meant that the cultural richness of Aboriginal and Torres Strait Islander peoples was excluded in their teaching. Such an omission thereby limits the cultural and historical knowledge base that underpins the key idea of 'value movement' in the Australian Curriculum Health and Physical Education (AC HPE) (ACARA, 2015). Given the nature of the findings this article is relevant to primary, middle and senior years.
\end{abstract}

\section{Introduction}

The purpose of this paper is to explore possible constraints experienced by Health and Physical Education (HPE) teachers in teaching Indigenous content in Physical Education (PE). In the broader Doctoral research that this study draws from, which was about how Indigenous students encounter PE, it was found that Aboriginal and Torres Strait Island perspectives were rarely taught in PE at the three schools investigated (Williams, 2016a). The silence of these perspectives is despite a requirement since the mid-1990s in Australian Capital Territory (ACT) government system level generic documentation or PE curricula to teach Indigenous perspectives (Williams, 2016b).

This paper investigates a PE figuration that comprises the PE programs, HPE teachers and Indigenous Education Officers (IEOs) at three government high schools in the ACT. The term figuration, or configuration, is used to describe relationships between individuals and processes with long-term processes in particular being important (Elias, 1978). Within the context of PE both small and large scale figurations exist. Small scale figurations are evident in every school and comprise networks of individuals that include the principal, HPE teachers, students and parents for example. Figurations like this have been shaped by tradition, differing and often competing discourses, policy and curricula as long-term processes (Williams, 2016b). 
An example of a figuration on a global scale is the idea of 'traditional PE' (Green, 1998). This version of PE, common in most Western countries, is characterised by a prevalence of team games and an accompanying skills based pedagogical approach. The concept of the figuration also asserts that human relationships are interdependent and characterised by power differentials (Elias, 1978). In other words, people within any given relationship have differing amounts of social power which is held and exercised relatively. The notion of relative power holds that no individual or group of people has absolute power (Elias, 1998). Instead of power being something that one person possesses and another does not, Elias (1998) instead considers power to exist as a balance in all human relationships. However, power balances are subject to change in the same way that figurations themselves alter over time on account of the intended and unintended consequences of people (Elias, 1978). Power relationships are important in PE and are evident in curriculum development for example. Historically PE curricula have been shaped through power struggles between writers and other stakeholders who have vested interests in what constitutes PE (Wright, 1996).

According to figurational sociology, figurations can be recreated for research purposes using three levels: macro, micro and sociogenesis (Baur \& Ernst, 2011). While the idea of using multiple levels is common to other theoretical frameworks used in investigating social issues in PE (Penney \& Evans, 2005) it is the sociogenesis level that makes figurational sociology distinctive (Baur \& Ernst, 2011). The sociogenesis level of a figuration represents its connection to the past. This temporal dimension is important because how PE/HPE teachers teach PE is inextricably linked to the past through long-term processes (Green, 2000a). Further, how PE is taught is influenced by a teacher's individual and social habitus (Green, 2000b; Williams, 2016a). Individual habitus, sometimes referred to as 'second nature' or 'personality make-up' (Mennell \& Goudsblom, 1998) describes aspects of personality that become deeply engrained in one's self which are learned in social situations as opposed to being innate within the individual. Although people possess an individual habitus they also have a social habitus (Elias, 1998; Mennell, 1994) through taking on behavioural characteristics typical of the people that form part of their social group. The concept of habitus is important to this research, because it is possible that HPE teacher perceptions of constraints in teaching Indigenous content are connected to their habitus. It is argued in the following literature review that HPE teachers develop a social habitus by being members of HPE faculties and departments that are established groups (Elias \& Scotson, 1994). Established groups are collections of people who have shared values, beliefs, behaviour and practices formed over time and who tend to have a relatively high share of the power resource (Elias, 1998; Elias \& Scotson, 1994) in the figurations that they are part of.

\section{Literature review}

In contemporary Australia, HPE teachers typically deliver technocratic PE (McKay, Gore \& Kirk, 1990; Meldrum \& Peters, 2012) while being 'time poor' from an increasingly widening curriculum (Morgan \& Hansen, 2008; Tinning, 2000). Technocratic PE emphasises the teaching of skills based content, or 'PE-as-sport-techniques' (Kirk, 2010) typically using modified team sports. Along with fitness and aspects of sports science, technocratic PE constitutes what Tinning (2004) refers to as privileged knowledge in PE. Conversely, marginalised knowledge (Tinning, 2004) in PE includes Dance and ethnicities. The latter term is used to describe any inclusion of Aboriginal and Torres Strait Island movement forms. The words 'any inclusion' are used here, because apart from the Northern Territory, there has historically been an absence of Indigenous perspectives in state and territory HPE curricula (Fitzpatrick, 2009). Technocratic 'PE-as-sport-techniques' (Kirk, 2010) can be considered a long-term process as it typifies the nature of PE in Australia for more than half a century. A further characteristic of Australian 
Technocratic PE is that it is Eurocentric, meaning that it favours Western knowledge with the viewpoints of other cultures largely discounted (Fitzpatrick, 2009). This enduring version of PE also tends to be repetitive and rarely progresses beyond the teaching of introductory knowledge and skill development (Kirk, 2010).

Pre-service HPE teachers in Australia having predominantly experienced Eurocentric technocratic PE throughout their own schooling tend to hold particular values, beliefs and expectations about what constitutes PE. For example, Tinning (2004) argues that these students often expect program content to reinforce their deep-seated interest and love of sport. This pre-disposition to sport is similar to what Green (2000a) found in his English study where PE teachers expressed a love for sport that was deeply engrained within their individual habitus. In the Australian pre-service HPE teacher context, when student teachers are taught marginalised content they are faced with the prospect of "becoming someone they don't [author's emphasis] want to become" (Tinning, 2004, p. 245) because such knowledge is often alien to their technocratic pre-conceptions about what PE means. Indeed, McKay, et al., (1990) comment that most PE degree students graduate with beliefs about PE that have been largely unaffected by PETE. Contemporarily PETE is more accurately termed HPETE in Australia because of the addition of Health to the PE subject area in the early 1990s (DinanThompson, 2006). Similarly, more recently, Currie (2014) commenting about HPE notes that “...most teachers have completed extensive training and preparation in performance studies and a range of practical physical activities and sports..." (pp. x-xi). Currie's observations demonstrate that the privileging of technocratic approaches continues to be part of a longterm process in HPETE. The literature also shows that university staff who design HPETE programs are constrained to offer PE specific units that have minimal delivery time allocated to them (Callcott, Miller \& Wilson-Gahan, 2015).This kind of limitation serves to further reduce opportunities to include marginalised knowledge.

Pre-service HPE teacher predispositions, particularly those associated with sport have a tendency to be welcomed and reinforced when students commence both teaching practicums and their initial teaching appointments. Sirna, Tinning and Rossi (2008) contend that "within a community of practice certain behaviours, attitudes, and dispositions are practiced, reinforced and encouraged while others may be marginalised, dismissed or even ridiculed" (p. 287). In other words, particular behaviours are valued as part of the social habitus of HPE teachers as an established group (Elias \& Scotson, 1994) within any given school HPE faculty or department. Pre-service PE/HPE teachers have been reported as seeking ways to gain acceptance by mentors and other teachers while completing practical teaching experience in schools (Keay, 2009; Sirna, et al., 2008). Expression of a common interest in Eurocentric sport was one way in which those students attempted to be included. As Elias and Scotson (1994) allude, people are often prepared to modify their beliefs in order to be admitted to a given established group figuration. In the Australian context such a compromise it is argued could be new teachers rejecting Indigenous traditional games that they may have learned as part of HPETE in order to 'fit in'. Similarly, Green (2000b) found that theoretical or academic constructs of PE had little bearing on English in-service PE teachers. Instead these teachers held ideologies or adopted taken-for-granted practices that were related to their individual habitus and also their social habitus through interdependencies with other PE teachers.

It has been argued in this brief literature review that what teachers do in teaching PE has been shaped to a greater or lesser extent by 'invented traditions' (Hobsbawm, 2012) continued and upheld by PE/HPE teachers as part of a long-term process. Further, these 'invented traditions' (Hobsbawm, 2012) relate to PE/HPE teacher individual and social habitus. 


\section{Method}

Figurational sociology was chosen as the theoretical framework to guide the research design and to analyse the findings. Figurational theory was appealing because it considers societal issues and problems processually. Alternative process theories such as Bourdieu's (1989) theory of habitus and field could have been used instead of figurational sociology. While Bourdieu's (1989) work was appealing because it is concerned with relationships of power and social inequity, figurational sociology was chosen due to relationships and processes being particularly emphasised (Depelteau, 2013; Dunning \& Hughes, 2013). Further justification for using figurational sociology is that the term habitus was used by Elias prior to its association with Bourdieu (Dunning, 2002; Dunning \& Mennell, 1996; Mennell \& Goudsblom, 1998; Paulle, Van Heerikhuizen \& Emirbayer, 2012).

A bi-cultural research design was adopted in keeping with the AIATSIS (2012) guidelines for ethical research. This approach involved the use of Indigenous Critical Friends who were IEOs or former IEOs at the three schools. The ICFs helped ensure that an Indigenous perspective was maintained throughout the study and they acted as a sounding board for cultural aspects of the research. A qualitative approach sympathetic to figurational sociology was used in this study. Although Elias used quantitative methods to some extent, he most often used qualitative approaches in his work (Dunning \& Hughes, 2013). Qualitative approaches were used in this study to enable a depth of understanding to be gained from research data.

Prior to data collection, ethics permission was obtained from University of Canberra Human Ethics in Research Committee and the ACT Education and Training Directorate. Data was subsequently collected using semi-structured individual and group interviews at each of the three school sites with all participants providing signed consent for their involvement. The confidentiality and anonymity of the research participants was safeguarded throughout the research and participants were able to withdraw without consequence at any time. Individual semi-structured interviews were used for the executive HPE teachers and semi-structured group interviews for the classroom HPE teachers and the IEOs. The HPE teachers were selected as participants because their viewpoints and perspectives were central to the study. The IEOs were chosen because they might perhaps offer differing accounts of the kinds of constraints that the teachers verbalised.

Three executive HPE teachers, 17 HPE teachers and three IEOs took part in this study. All twenty teaching staff were non-Indigenous and the three IEOs were Aboriginal. There were 14 male teachers and six female teachers and all three IEOs were male. One IEO had heritage from Northern New South Wales (NSW), Southern Queensland and Central Western NSW. Another descended from the Nuenonne people of the South East coast of Tasmania (his mother's family) and the Gubbi Gubbi people of the South East coast of QLD (his father's family). The third IEO was of the Kamilaroi people.

Data was analysed using thematic analysis (Bryman, 2012) by identifying key themes that emerged in participant transcripts about perceived constraints in teaching Indigenous perspectives in PE. In order to protect the identities of the participants and the schools, the teachers and IEOs are identified in the following section by a separate number and with the letter ' $A$ ', ' $B$ ' or ' $C$ ' denoting which school they belonged to.

\section{Results and discussion}

In analysing the findings figurational sociology was used to identify power relationships, specifically where teachers were able to demonstrate relative power. The HPE teachers mentioned a number of constraints that they said made it challenging for them to include 
Indigenous perspectives in their teaching. At each of the schools the HPE executive and classroom teachers said that they had either no knowledge, or limited knowledge of Indigenous games and physical activities.

\section{Time poor}

A lack of time was a recurring theme across all three sites with regard to the day-to-day operation and work within HPE faculties. This reported lack of time is consistent with what is noted earlier in the literature review (see Morgan \& Hansen, 2008; Tinning, 2000). An example of the nature of lack of time was offered at school B:

It's about actually having that time... to step back and reflect on our actual practices and say 'yep, with this little bit of tweaking we could do this better or... we could... make sure that everyone had an opportunity to learn this'. It's just like go, go, go, status quo. This is what we've been doing. Let's just keep doing because... we don't have time really to sit back and reflect (teacher 3B).

Executive teacher B also commented about the lack of time that HPE teachers had to make any changes to existing provision. Similarly, at School C, the executive teacher remarked:

I'll acknowledge straight away I'm time poor. Yeah I don't give any advice on time management. I think the problem is trying to squeeze too many things in the one day. So you know... trying to do 50 things in a day instead of doing 10 things a bit more deep.

It is argued that the pressure of time reported by these HPE teachers in delivering the established curriculum is not conducive to adding, what was regarded as 'new content' in the form of Indigenous perspectives.

\section{Resources}

There appeared to be a lack of knowledge amongst the HPE teachers about the resources that were available for teaching Indigenous games, sports and other physical activities in PE. For example, executive teacher B was unaware of the existence of the Yulunga (ASC, 2009) resource for teaching Indigenous games and in response to being informed about it said:

So it's alright to have a 200 page document on the web... but teachers aren't going to look at it... because you know... it's not being 'delivered right to their door'... whereas in other areas we just have that knowledge I suppose... or somehow that we've developed.

What is evident in the above comment is some notion of PE knowledge accumulating over time and being passed down as part of an ongoing and lasting process. It is also implied that privileged content (Tinning, 2004) is sufficient for teaching PE and alternative knowledge is not required. In contrast, executive teacher $C$ knew about the Yulunga (ASC, 2009) resource:

The IEO has sort of brought... well not just the IEO, we were aware of it before. But I would have to be honest with you that we probably could have used more... games out of that... than we probably have. 
However, similar to executive teacher $B$, executive teacher $C$ thought that HPE teachers tended to not make use of resources:

... even though there's the resource (Yulunga)... and then... how long does it sit on a shelf for... before we actually... unless someone has got the initiative... or the foresight to... keep people up to speed with it...

Again, there was the notion in this response that 'time poor' was a reason for not including Indigenous perspectives, as well as the current knowledge stock being adequate for delivering the curriculum. None of the teachers at School A or B knew about Yulunga (ASC, 2009).

\section{Professional development}

A lack of professional learning was raised by executive and classroom HPE teachers across the three sites.

I think probably like a professional development, or a course on it [teaching Indigenous perspectives in PE] would be ideal, before going into something like that [teaching Indigenous content in PE]. I guess really... you know you could 'wing it,' but... you really wouldn't have that basic understanding (teacher 5A).

Similarly, executive teacher A commented:

Okay, so fitting [Indigenous content] into the curriculum [PE]... would be no drama. But once again it's that time to be able to do the professional development... to 'up skill' us in doing that to be able to teach it... l'd like to get someone like our IEO... who's really good... to actually come in and 'in service' us which would be brilliant.

At school C:

... I think probably really what's needed across the whole system to be honest... is professional development. You've probably heard that before, specific professional development... to... not convince... but to... make phys ed teachers aware of the variety of activities (executive teacher $\mathrm{C}$ ).

Although the executive and classroom HPE teachers expressed a desire for professional learning and not withholding comments from some participants about being disinclined to utilise resources, Yulunga (ASC, 2009) is written for use by Indigenous and non-Indigenous HPE teachers. It is produced in lesson plan format in what can perhaps be described as Australian Sports Commission 'house style.' There are over 130 games listed that are signposted according to the school Year group/s that they are suited for. Each game uses contemporary sports equipment and is presented through text and diagrams. There are sections on how to play, rules, safety, equipment, variations and teaching points (ASC, 2009). Further, the games are organised within the resource in such a way that they correspond to a range of fundamental movement skills that teachers would be familiar with, including throw, catch, vertical jump, run, single and two-arm striking. In addition, some of the games encourage co-operative physical activity where there is no scoring involved. Therefore the need for professional development is perhaps not as necessary as the teachers suggest. A rather impassioned comment was made by one of the IEOs at their interview, mentioned later, that HPE teachers just need to learn the rules for Indigenous games and start teaching them in their classes. In other words, these 
teachers need to learn the rules for Indigenous games in much the same way as they do for the approximately 40 Eurocentric sports or physical activities that are approved for teaching in the Physical education and sport policy and implementation guidelines (ACT DET, 2009). The idea of professional learning to be able to teach all 40 games detailed in these guidelines would be unrealistic and impractical. Further, it was suggested by this IEO that the teachers could learn Indigenous games by referring to Yulunga (ASC, 2009).

\section{Support}

Lack of support from school management was regarded as a constraint for including Indigenous content:

Money, resources, support from... people who need to support us. We can offer lots of things at this school... but if we're the only people who wanted it... it's not going to happen. So we've got to have people higher up the 'food chain' ready to support it... provide the time for the training which is a pressure in every school for professional development (teacher 5B).

Within this comment there was again a sense that Indigenous content is not 'core business' or privileged knowledge (Tinning, 2004). Instead, it is something that with 'appropriate support' has the potential to be added to the curriculum. This comment is despite the requirement to include Indigenous content in PE mentioned in PE specific ACT government curricula or generic system level policy documents since the mid-1990s (Williams, 2016b). IEO C expressed similar sentiments suggesting that greater direction from education management and organisations such as ACT Secondary School Sports Association (ACT SSSA) would help:

I think more directive from authority... to say 'you must do this'... and now with the SSSA... they're an authority here... they should be sending that authority out to every PE staff... in secondary school and say... 'you must' [the words 'you must' emphasised]... invite an IEO... or you must... implement... these games in your curriculum... Because otherwise they'll just go on... because you've got to remember teachers just write up their own lesson plans... what they want to teach.

This response by IEO C draws attention to the relative power (Elias, 1998) that HPE teachers possess, through being able to teach the content that they value most. Indeed, content that also corresponds to their individual and social habitus (Elias, 1998; Mennell, 1994).

\section{Pre-service physical education teacher education}

A common theme across all three schools stated by the HPE executive teachers and teachers, was that Indigenous content was not included in the specialist PE subjects as part of HPETE:

It's not covered in any of the courses that we study at university and I think it should be. I mean that's where it should start. So I think our issue is that we don't have... a really big background like we do in some of our traditional sports and that's where it has to start... so that we feel comfortable in teaching it. So we'd love to teach it... but we need to have the knowledge to be able to teach it... (executive teacher A). 
Likewise, about the nature of contemporary PE at their school, executive teacher B remarked:

Whereas in other areas we just have that knowledge I suppose... or somehow that we've developed.

In other words, the habitus of the teachers in this study was oriented towards Eurocentric sport and the kind of technocratic PE described in the literature review. The teachers commented that the only Indigenous content that was covered during their HPETE was in a generic unit that never provided them with PE specific information:

As far as that's concerned [Indigenous perspectives in PE] that's all good and I'm happy to include it... but as we've said... how do we include it if we've never been exposed to it? At uni we did 'Indigenous Education - What Works'... and it was the worst unit that I have done... because it was... us getting up and talking about... different cave paintings and different things... and that's fine... but the name of the unit was 'Indigenous Education What Works'... you'd think that there'd be some sort of practical application... what can we do to help Indigenous kids... learn in 'our scene' (teacher 7B).

Similarly:

Yeah, but it doesn't tell you anything [Indigenous Education What Works]... Like it's not helpful at all... But in terms of PE like 'chucking it' in the PE curriculum at uni, you definitely want to do something like that. Like classroom strategies and then you'd want to do the games and... even right down to the Dance... you'd have someone come in and stuff, but they [university] don't do anything like that (teacher 5C).

IEO B, concerning HPETE remarked:

...certainly I picked up in the schools... there's probably a fear... amongst nonIndigenous teachers... because... you know all through university they haven't learned a whole lot about all this stuff and I think they're afraid of doing these things wrong... that's why they're so reliant on us [the IEOs]... it doesn't need to be intimidating... like you come out and watch Buroinjin [an Aboriginal traditional game]... it's pretty universal... you know... Yeah and all the kids enjoy it. It's not just an Indigenous 'thing'. It's just a game that happened to be played before colonisation....

Similarly, commenting about in-service HPE teachers IEO C mentioned with some frustration and passion:

... teachers should teach Indigenous games same way they teach any other game... by the f'n rules that are written down in the guidelines [Yulunga, ASC, 2009]. For a teacher to teach rugby league they've got to know the rules. For a teacher to teach Aussie Rules they've got to know the rules. Cricket they've got to know the rules. So it's just pretty simple... the teachers have to learn the rules to Aboriginal games and f'n implement them in their f'n classes. 
The lack of Indigenous mention in HPETE that the HPE teachers comment about is perhaps due in part to the kinds of constraints experienced by HPETE educators discussed by Callcott, et al. (2015). In particular, decisions are made by non-HPE specialist program providers about what to include in the PE specific content of HPETE programs that typically have limited time allocation. As an Indigenous focus was only included in a single generic unit, it suggests that privileged content (Tinning, 2004) was deemed by the course providers as being more important within the PE subjects. In other words, it seems that privileged content took priority in the restricted space that was available in the HPETE program. The omission of PE specific Indigenous perspectives demonstrates the relative power (Elias, 1998) of those responsible for the program design and delivery. Also, it can be reasonably assumed that those lecturers and tutors would have had individual and social habitus that were heavily informed by Eurocentric activities, given the history of PE and school sport in Australia.

\section{Synthesis}

The teachers spoke about how they would teach Indigenous content in PE in the future as if it was a new requirement for them to include these perspectives. The nature of this expression is perhaps understandable because the system level curriculum document that the teachers were using at the time, Every Chance to Learn (ACT DET, 2007) made no mention of the words Aboriginal, Torres Strait Islander or derivatives of these words or the word Indigenous in the PE related section. However, in other policy documents such as the Aboriginal and Torres Strait Islander Strategic Plan 2010-2013 (ACT ETD, 2010) it is stated that all teachers are required to incorporate Indigenous content in their respective Key Learning Areas (KLAs).

Long-term pre-dispositions to Eurocentric sport contributed to the individual and social habitus of the teachers in this study. A lack of exposure to Indigenous content in HPETE, along with no professional learning and the absence of Indigenous mention in the PE content of Every Chance to Learn (ACT DET, 2007) together partly accounted for Indigenous perspectives being absent in most of the teachers' PE lessons. Further, Consistent with the literature, the HPE executive and classroom teachers worked in a busy environment with multiple demands that contributed to them being 'time poor'. Nonetheless, these teachers were still able, despite these environmental constraints, to teach privileged content that fitted with their individual and social habitus.

\section{Summary, conclusions and implications}

In answering the research question, the author contends that while there were legitimate constraints preventing Indigenous content from being taught as a regular part of PE, these obstacles reflected the nature of HPE teaching more generally. In other words, the constraints that the HPE teachers spoke about were not unique to teaching Indigenous perspectives. Those teachers had to overcome the same kinds of constraints, including accepting and responding to a lack of professional learning in all aspects of HPE, in order to carry out their day-today teaching responsibilities. It is contended by the author that the individual and social habitus of the teachers accounted for 'policy slippage' in the kind of PE that was taught. The HPE executive and classroom teachers in this research would have only known technocratic PE in their lived memories from their childhood experiences. This lack of exposure to Indigenous content in their own schooling would have been reflected during HPETE. For these teachers, Indigenous content was alien through a lack of contact in their personal and professional lives. However, by not following directives in system level policy documents about incorporating Indigenous content in all KLAs, the HPE teachers demonstrated their relative power within the figuration. 
It is contended by the author that if HPE teachers and curriculum writers as well as HPETE providers do not work towards addressing the silence of Indigenous perspectives in PE, then valuing movement as a key idea in the AC HPE (ACARA, 2015) will occur only within the context of Eurocentric knowledge. There is renewed opportunity through the AC HPE (ACARA, 2015) for Indigenous content to be meaningfully taught to all Australian children thereby addressing the equity goals of the Melbourne Declaration on Educational Goals for Young Australians (Ministerial Council on Education, Employment, Training and Youth Affairs, 2008). In addition, including this content in a substantive and non-tokenistic way, while adding to the existing stock of Eurocentric PE can help address concerns reported in the literature about PE being repetitive and lacking variety. However, for Indigenous perspectives to be incorporated meaningfully in PE and in HPE more broadly, a multi-faceted approach is required otherwise things are likely to remain much as they are.

Since data was collected for this paper, Indigenous content has been explicitly taught to HPE student teachers in PE specific units at the HPETE university local to where this study took place. If Indigenous content is substantively taught in primary and secondary school PE as a consequence of this PE specific teacher education, then future HPE teachers will learn Indigenous games and sport in their childhood education. These possible future childhood encounters of Indigenous content in PE are important because they could contribute to the individual habitus of future HPE teachers through Indigenous content becoming 'normalised'. As such, Indigenous content changes status by becoming privileged knowledge (Tinning, 2004) through the wider figuration of Australian PE altering in common with all figurations (Elias, 1998). In addition to changes at the HPETE level, professional learning was delivered at the Australian Council for Health, Physical Education and Recreation (ACHPER) ACT 2016 conference about teaching Indigenous perspectives in PE.

In conclusion, the author contends that Indigenous perspectives such as the kinds of games and physical activities included in Yulunga (ASC, 2009). This particular content can make an important contribution to 'value movement' as a key idea within the AC HPE (ACARA, 2015) by acknowledging and placing importance on activity that is not exclusively from the Eurocentric stock of knowledge. An area of further study is to investigate what else can be done to alter HPE teacher habitus so that Indigenous perspectives are genuinely accepted and embedded in the AC HPE (ACARA, 2015). As a relatively recent migrant to Australia, having moved from Scotland eight years ago at the time of writing, Indigenous games are appealing for inclusion in Australian PE content. I have used many of the games from the Yulunga (ASC, 2009) resource as a former HPE secondary school teacher and also in HPETE workshops more recently as a teacher educator. Further, I have found few challenges in using this resource to teach Indigenous perspectives in PE and have observed that my students, Indigenous and non-Indigenous alike, have enjoyed playing something different from what they usually do in PE. 


\section{References}

ACARA (Australian Curriculum Assessment and Reporting Authority). (2015). The Australian curriculum health and physical education. Retrieved from http://www.australiancurriculum.edu.aul health-and-physical-education/curriculum/f-10?layout=1

ACT DET (Australian Capital Territory Department of Education and Training). (2007). Every chance to learn: Curriculum framework for ACT schools preschool to year 10. Canberra: Publishing Services for the ACT Department of Education and Training.

ACT DET (Australian Capital Territory Department of Education and Training). (2009). Physical education and sport policy and implementation guidelines. Canberra: Publishing Services for the ACT Department of Education and Training.

ACT ETD (Australian Capital Territory Education and Training Directorate). (2010). Aboriginal and Torres Strait Islander education matters strategic plan 2010-2013. Canberra, Australia: Author.

AIATSIS (Australian Institute of Aboriginal and Torres Strait Islander Studies). (2012). Guidelines for ethical research in Australian Indigenous studies. Retrieved from http://aiatsis.gov.au/sites/default/ files/docs/research-and-guides/ethics/GERAIS.pdf

ASC (Australian Sports Commission). (2009). Yulunga. Retrieved from http://www.ausport.gov.aul_data/ assets/pdf_file/0017/402191/SP_31864_TIG_resource_FINAL.pdf

Baur, N. \& Ernst, S. (2011). Towards a process-oriented methodology: Modern social science research methods and Norbert Elias's figurational sociology. The Sociological Review, 59(s1), 117-139. doi:10.1111/j.1467-954X.2011.01981.x

Bourdieu, P. (1989). Social space and symbolic power. Sociological theory, 7(1), 14-25.

Bryman, A. (2012). Social research methods (4th ed.). Oxford, England: Oxford University Press.

Callcott, D., Miller, J., \& Wilson-Gahan, S. (2015). Health and physical education: preparing educators for the future. Cambridge University Press.

Currie, J. L. (2014). Teaching health and physical education in secondary school. Camberwell, Australia: Australian Council for Educational Research.

Dépelteau, F. (2013). Comparing Elias and Bourdieu as Relational Thinkers. In Norbert Elias and Social Theory (pp. 275-295). Palgrave Macmillan US.

Dinan-Thompson, M. (2006). Why the KLA? And why now? In R. Tinning, L. McCuaig \& L. Hunter (Eds), Teaching health and physical education in Australian schools (pp. 25-39). Frenchs Forest, Australia: Pearson Education.

Dunning, E. \& Hughes, J. (2013). Norbert Elias and modern sociology: Knowledge, interdependence, power, process. London, England: Bloomsbury Academic.

Dunning, E. \& Mennell, S. (1996). Preface. In N. Elias (Ed.), The Germans: Power struggles and the development of habitus in the nineteenth and twentieth centuries. New York, NY: Columbia University Press.

Dunning, E. (2002). Figurational contributions to the sociological study of sport. In J. Maguire \& K. Young (Eds), Theory, sport and society (pp. 211-238). Oxford, England: Elsevier Science.

Elias, N. \& Scotson, J. L. (1994). The established and the outsiders (Vol. 32). London, England: Sage Publications.

Elias, N. (1978). The civilizing process: The history of manners. Oxford, England: Basil Blackwell.

Elias, N. (1998). Game models. In S. Mennell \& J. Goudsblom (Eds), Norbert Elias on civilization, power, and knowledge: Selected writings (pp. 113-138). Chicago, IL: The University of Chicago Press. 
Fitzpatrick, K. (2009). Indigenous perspectives in HPE curriculum: Contradictions and colonisation. In M. D. Thompson (Ed.), Health and physical education: Issues for curriculum in Australia and New Zealand (pp. 120-144). South Melbourne, Australia: Oxford University Press.

Green, K. (1998). Philosophies, ideologies and the practice of physical education. Sport, Education and Society, 3(2), 125-143. doi:10.1080/1357332980030201

Green, K. (2000a). Extra-curricular physical education in England and Wales: A sociological perspective on a sporting bias. European Journal of Physical Education, 5(2), 179-207. doi:10.1080/1740898000050206

Green, K. (2000b). Exploring the everyday 'philosophies' of physical education teachers from a sociological perspective. Sport, Education and Society, 5(2), 109-129. doi:10.1080/713696029

Hobsbawm, E. (2012). Introduction: Inventing traditions. In E. Hobsbawm \& T. Ranger (Eds), The invention of tradition (pp. 1-14). New York, NY: Cambridge University Press.

Keay, J. (2009). Being influenced or being an influence: New teachers' induction experiences. European Physical Education Review, 15(2), 225-247. doi:10.1177/1356336X09345235

Kirk, D. (2010). Defining physical education: Nature, purposes and future/s. Physical Education Matters $5(3), 30-31$.

McKay, J., Gore, J. M. \& Kirk, D. (1990). Beyond the limits of technocratic physical education. Quest, 42(1), 52-76. doi:10.1080/00336297.1990.10483979

Meldrum, K. \& Peters, J. (2012). Learning to teach health and physical education: The student, the teacher and the curriculum. Frenchs Forest, Australia: Pearson.

Mennell, S. \& Goudsblom, J. (1998). Introduction. In S. Mennell \& J. Goudsblom (Eds), Norbert Elias on civilization, power, and knowledge: Selected writings (pp. 1-45). Chicago, IL: The University of Chicago Press.

Mennell, S. (1994). The formation of we-images: A process theory. In C. Calhoun (Ed.), Social theory and the politics of identity (pp. 175-197). Oxford, England: Blackwell.

Ministerial Council on Education, Employment, Training and Youth Affairs. (2008). Melbourne declaration on educational goals for young Australians. Retrieved from http://www.curriculum.edu.au/verve/_ resources/national_declaration_on_the_educational_goals_for_young_australians.pdf

Morgan, P. J., \& Hansen, V. (2008). Classroom teachers' perceptions of the impact of barriers to teaching physical education on the quality of physical education programs. Research Quarterly for Exercise and Sport, 79(4), 506-516.

Paulle, B., Van Heerikhuizen, B. \& Emirbayer, M. (2012). Elias and Bourdieu. Journal of Classical Sociology, 12(1), 69-93. doi:10.1177/1468795X11433708

Penney, D., \& Evans, J. (2005). Policy, power and politics in physical education. Physical education: Essential issues, 21-38.

Sirna, K., Tinning, R. \& Rossi, T. (2008). The social tasks of learning to become a physical education teacher: Considering the HPE subject department as a community of practice. Sport Education and Society, 13(3), 285-300. doi:10.1080/13573320802200636

Tinning, R. (2000). Seeking a realistic contribution: Considering physical education within HPE in New Zealand and Australia. Journal of Physical Education New Zealand, 33(3), 8-21.

Tinning, R. (2004). Rethinking the preparation of HPE teachers: Ruminations on knowledge, identity, and ways of thinking. Asia-Pacific Journal of Teacher Education, 32(3), 241-253. doi:10.1080/1359866042000295406 
Williams, J. (2016a). 'I didn't even know that there was such a thing as aboriginal games': a figurational account of how Indigenous students experience physical education. Sport, Education and Society, 1-13. doi: 10.1080/13573322.2016.1210118 Retrieved from http://www.tandfonline.com/ doi/abs/10.1080/13573322.2016.1210118

Williams, J. (2016b). Invented tradition and how physical education curricula in the Australian Capital Territory has resisted Indigenous mention. Asia-Pacific Journal of Health, Sport and Physical Education, 7(3), 219-234. doi: 10.1080/18377122.2016.1233803 Retrieved from http://www. tandfonline.com/doi/abs/10.1080/18377122.2016.1233803

Wright, J. (1996). Mapping the discourses of physical education: Articulating a female tradition. Journal of Curriculum Studies, 28(3), 331-351. doi:10.1080/0022027980280306 